\title{
Paradox of Richness: A Cognitive Model of Media Choice
}

\author{
- LiONel P. Robert AND Alan R. DENNIS
}

\begin{abstract}
Researchers have long studied the effects of social presence and media richness on media choice and the effects of media use. This focus on social presence and social psychological theories has led to valuable research on communication. However, little research (either empirical or theoretical) has been done to understand the ways in which media choices influence the cognitive processes that underlie communication. In this paper, we present a cognitive-based view of media choice and media use, based on dual process theories of cognition, which argue that in order for individuals to systematically process messages, they must be motivated to process the message and have the ability to process it. We argue that the use of rich media high in social presence induces increased motivation but decreases the ability to process information, while the use of lean media low in social presence induces decreased motivation but increases the ability to process information. The paradox of richness lies in its duality of impact: from a cognitive perspective, rich media high in social presence simultaneously acts to both improve and impair performance.
\end{abstract}

Index Terms-Communication, decision making, elaboration likelihood model (ELM), heuristic systematic processing, information overload, media choice, message complexity, social presence, teams.

In order to better understand media effectiveness, we as researchers have to shift our attention from the communication medium itself to assessing the "balance between the medium and the message" [1, p. 251].

Increasingly, as geographically dispersed individuals communicate via computer, understanding the effectiveness of media in general becomes more important. Researchers have long studied the effects of social presence and media richness on media choice and the effects of media use. Two theories, the social presence theory [2] and the media richness theory [3], have been the most prominent theories used to explain rational media choice [4].

The social presence theory argues that media differ in the ability to convey the psychological perception that other people are physically present [2]. Some mediums (e.g., videoconferencing or telephone) have greater social presence than other mediums (e.g., email), and the use of media higher in social presence should be important for social tasks such as building relationships.

The media richness theory [3], which builds on the social presence theory [5], argues that communication media differ in their ability to facilitate understanding. It was the media's "information richness," defined as the amount of information a medium could convey to change the receiver's "understanding within a time interval," that differentiated richer media from leaner

Manuscript received March 1, 2004; revised July 25, 2004. The authors are with the Kelley School of Business, Indiana University, Bloomington, IN 47405 USA (email: lrobert@indiana.edu).

IEEE DOI 10.1109/TPC.2003.843292 media [3, p. 560]. The use of richer media would lead to better performance for tasks with greater equivocality or ambiguity.

However, with the introduction of new media, many studies testing the social presence theory and the media richness theory in new media are finding mixed or conflicting results [5]-[9]. An early meta-analysis of 241 studies determined that a high degree of social presence increased the accuracy and speed of simple, well-known tasks but hindered the speed and accuracy of less-known, complex tasks [10]. Baron's distraction conflict theory (DCT) offers a cognitive-based explanation for these results [11]. High social presence can become a distraction, which forces individuals to narrow their attention on the task at hand. This increase in attention focusing could facilitate performance in simple tasks by filtering out irrelevant cues, resulting in an increase in speed and accuracy. However, as the number of relevant issues to consider (i.e., complexity) increases, a sender's ability to mentally manage these issues decreases. As a result, an individual may ignore important cues needed to accomplish more complex tasks, reducing task performance.

In other words, we believe there is a paradox embedded within the use of rich media. A high degree of social presence in rich media may aid in the communication of simple ideas but hinder the communication of complex ideas. Although DCT did not explicitly focus on communication, we believe this theory is applicable in this domain and may help explain the conflicting results from prior research [11].

The focus on social presence and media richness has led to valuable research in the social processes 
of communication, which primarily focus on the receiver's perception and interaction with the sender. Unfortunately, little has been done to understand the cognitive processes of communication. We believe that to better understand how media effects a change in understanding, an approach based on cognitive psychology can offer additional insights to those offered by more traditional approaches solely based on social psychology. The cognitive processes that underlie such behaviors as learning, attention, problem solving, and decision making offer new lenses through which one can view how communication media affect our ability to facilitate understanding.

In an effort to understand this process, we used the elaboration likelihood model (ELM), one of the dual process theories of cognition as our fundamental theoretical framework [12]. One of the most widely used cognitive theories, ELM posits that in order to change someone's understanding and attitude, the receiver has to be motivated to think about the message and has to have the ability to process the message (i.e., devote cognitive effort to the message).

In this paper, we explain how media, based on their levels of social presence, either support or hinder motivation and the ability to process. It is our belief that by matching the appropriate media with the message, an individual can increase his or her chance of changing the attitude of the receiver. It is our hope that in this paper we can provide a new theoretical understanding that can help explain the conflicting results based on the application of media richness to new media and provide a model for the currently underinvestigated cognitive approach to media research. The following section reviews prior media research; next, the theoretical development is introduced; then, the implications of the model are discussed. Finally, we conclude with a call for more cognitive-based research.

\section{Past Research}

In 1978, Short et al. introduced the social presence theory, which argued that a medium's effectiveness centered on its ability to communicate the character of the relationship between the sender and receiver, defined in such terms as sociability, personalness, warmth, and sensitivity [2]. Media low in social presence, such as memos, were good for providing information, while media high in social presence, such as face-to-face discussions, were better suited for negotiations [2], [13]. In 1981, Daft and Macintosh introduced a model that began to explain the relationship between the amount and equivocality of information with the variety and analyzability of a given task [14]. However, it was not until Daft and Lengel [3], [15] that an overarching, integrated media theory was proposed, based primarily on the social presence theory [5]. Specifically, in 1986, Daft and Lengel asked: Why do organizations process information? The answer, they found, was to reduce uncertainty and equivocality [3]. Uncertainty was characterized as the lack of information while equivocality was defined as "ambiguity" [3]. Out of this emerged the media richness theory, which posits that to increase organizational performance, an organization must match the appropriate media with the appropriate tasks [3], [15].

Originally, the media richness theory was a "prescriptive model" used to determine the appropriate match between media and tasks, but it has evolved into a "descriptive model" explaining how managers match media to tasks [16]. The media richness theory is based on the premise that media varies in its ability to effect a change in the receiver's understanding [14], [15]. The richness of the media is based on a mixture of four criteria: feedback, multiple cues, language variety, and personal focus. The media richness theory proposes that the use of richer media for tasks described as high in equivocality will result in better performance of those tasks. Face-to-face communication is described as the richest medium under both media richness and the social presence theory and, therefore, is preferred for highly equivocal tasks, while email and memos, described as leaner, are preferred for nonequivocal tasks.

The first in a long line of empirical tests of media richness began with Daft et al. [15]. Since then, the studies performed can be broken into two categories: those supporting media richness [17]-[21] and those finding mixed or no support of media richness [5], [16], [22]-[29]. In particular, media richness has been criticized for not considering situational factors that could potentially affect behavior [30] and social factors that may alter an individual's perception of the media [26].

To explain the inconsistencies in the above findings and to account for situational factors and social factors, Carlson and Zmud introduced the channel expansion theory [31]. The channel expansion theory recognizes that there are specific experiences that influence how individuals develop "richness perceptions" for a given media channel [31]. They identified four experiences as being most important: channel experience, message topic experience, organizational context experience, and communication coparticipants experience. The channel expansion theory posits that as individuals gain experience in each area-channel, message topic, organizational context, and communication coparticipants - they are able to use the media more effectively, and, as a result, their perceptions of the richness of the media change. Although Carlson and Zmud found general support for their overall theory, they found only partial support for the influence of organizational context experience and little support 
for message topic experience [31]. Carlson and Zmud's channel expansion theory accounted for the situational aspects of the social communication process, but very little has been done to address the original premise of the media richness theory: media's ability to effect a change in understanding. By taking a cognitive approach and understanding the cognitive factors that underlie attitude change, researchers may be better able to answer research questions pertaining directly to media's effectiveness.

Two dimensions can be used to classify the extent of social presence or media richness perceived by the users of a medium: spatial and temporal [32]-[34]. The spatial dimension is divided into same space, in which the sender and receiver are required to be at the same location to use the media, and different space, in which the sender and receiver are not required to be at the same location to use the media. Time, the second dimension, is divided into same time and different time. Same time requires the sender and receiver to communicate simultaneously. Different time does not require simultaneous communication. In general, media providing same-time and same-place interaction are perceived to be higher in social presence and media richness than media providing different-time and different-place interaction [2], [15].

\section{THEORY DEVELOPMENT}

ELM Our work builds on the dual process model of cognition. Contemporary researchers have acknowledged that there are two dual process models that share many common elements: the ELM [35]-[37] and the heuristic systematic model [38]-[40]. Both process models recognize that attitudes are formed either by the systematic application of considerable cognitive effort, in an attempt to comprehend and evaluate the validity of available information, or by exerting little cognitive energy, by using simple heuristics on readily accessible information [35]-[40]. The systematic route yields more enduring judgments that are founded on close examination of the merits of the arguments presented. The second is based on little, if any, examination of the merits of an argument and results in a temporary attitude shift. Dual process models posit that the path an individual will use is determined by any number of factors such as message relevance, prior knowledge, and available time [41]. Since both models complement each other and ELM was much more comprehensive, we adopted the ELM model for this paper.

ELM, introduced by Petty and Cacippo [35], [36], provides a framework for organizing, categorizing, and understanding basic processes underlying the effectiveness or persuasiveness of communication. ELM was designed to incorporate current and past conflicting research findings and theoretical orientations under one conceptual umbrella. ELM defines elaboration in a persuasion context, (i.e., the extent to which a person considers the issue-relevant arguments embodied in a message) [35], [36]. Petty classifies all literature on attitude persuasion into two separate routes to persuasion [39]. The first route, called the central route, results from thoughtful evaluation of the merits of the information presented. The second, called the peripheral route, occurs without the thoughtful examination of the true merits of the information presented [35], [36].

Petty and Cacippo posit that motivation and the ability to process the information determine which route individuals will employ [35], [36]. In circumstances where individuals are motivated and have the ability to process information, they will engage in issue-relevant thinking. When this occurs, individuals are likely to attempt to access relevant associations, images, and experiences from memory and analyze and elaborate on the information presented in conjunction with the associations provided from memory. Individuals may also extract inferences concerning the merits of the arguments in support of a recommendation centered on their examination and develop an overall evaluation of or attitude toward the information [35], [36]. Because the individual is integrating the arguments presented with their previous knowledge, elaboration likelihood is high, and there will be considerable support for the allotment of cognitive effort [35], [36].

If the message is perceived as a strong and compelling argument, then thinking about the information in the message will cause favorable thoughts to be rehearsed, and an enduring persuasion will result. However, if the person perceives the arguments as weak and not compelling, then thinking about them will cause counterarguments to be rehearsed and as a result, the opinion or attitude may move away from the position advocated in the message.

In contrast, in circumstances where individuals are not motivated or do not have the ability to process information, they will not allocate processing effort toward a received message and will not fully integrate the information with their previous knowledge. When this occurs, the elaboration likelihood is describe as being low. Rather than thinking deeply about the message, the receiver will attempt to shortcut the process by using simple heuristic rules based on peripheral cues that originate from the source of the message, the message itself, the sender of the message, the channel used to send the message, and the context in which the message was sent. These peripheral persuasion cues include attractiveness of the source, source creditability, and the number of coherent arguments contained in the message [35], [36].

Petty and Cacioppo posit that arguments that pass through the central route will result in enduring, resistant, and predictable behavior changes, while arguments that pass through the peripheral route will only result in temporary, susceptible, and unpredictable behavior changes [35], [36]. Unless 
individuals fully consider the messages they are presented with, they cannot constantly make good decisions based on the information. The basic premise of this paper is that high elaboration will lead to better decision making between individuals performing decision, problem, and judgment tasks within an organization/work team environment. We preface this with the assumption that the sender wants the unbiased opinion of the receiver.

Proposition 1 The extent of elaboration is positively related to decision quality.

Attention and Motivation Attention is an important part of the communication process. In Thorngate's "The economy of attention," the first axiom is that "we must pay attention to be informed" [42, p. 263]. Attention is what receivers pay to consume information and convert it into knowledge. The sender must have the receiver's attention before any part of the communication process can begin. Communication is not only an exchange of information but also an exchange of attention, and different media present different usage costs to the receiver [42].

In general, the greater the social presence of the media, the greater the degree of commitment the receiver has to make to participate in the communication process. The cost to use a medium ranges from relatively high, when individuals must obligate themselves to a specific location and time, to relatively low, when individuals are not obligated to any specific location or time. For example, media classified as same time same space (e.g., face-to-face discussion) requires a higher level of commitment on the part of the receiver, who must be physically present at a specific place and time to communicate, than media classified as different time, different space (see Fig. 1).

All things being equal, it is reasonable to argue that since the receiver is willing to pay a higher cost to use the medium, the receiver must be motivated

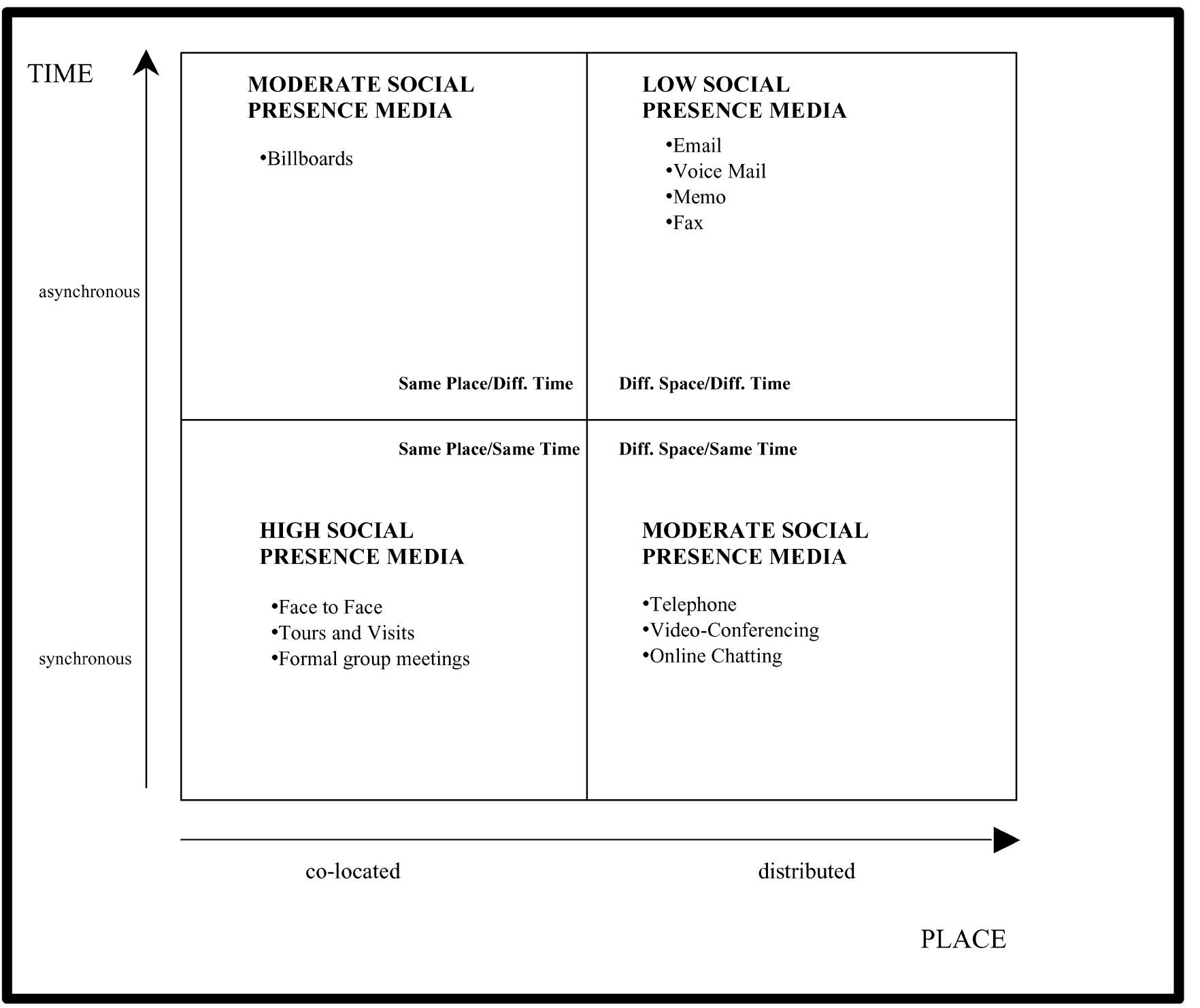

Fig. 1. Media classification. 
to process the message. If the receiver were not motivated, then the receiver would be less likely to pay the cost to use the medium [7].

Media with a greater social presence also provide the message sender with a greater ability to monitor the receiver's reaction to the message [5], [43]. While it is possible for the sender to pretend to pay attention to the receiver while actually devoting attention elsewhere, media with a greater social presence make this more difficult than media with lower social presence. While one can read a report while pretending to read email or listen to a telephone conversation, it is more difficult to do so successfully while speaking to someone face-to-face or in a videoconference. In essence, the ability to monitor attention is linked to media.

When using a high social presence media, the receiver has to commit some portion of his or her attention to the message and will therefore be more likely to be motivated to hear it. As individuals increase their level of attention, the effort and intention devoted to the communication process increases. In the words of Petty and Cacioppo, "if both intention and effort are present, then motivation to think about the advocacy will exit" [36, p. 220]. Therefore, the greater the social presence of a medium, the greater the receiver's motivation has to be to listen to the message. For example, if someone knocks on your door and you allow him or her to enter, he or she now has your attention. If you agree to begin a conversion, you have shown motivation to hear the message and begin the elaboration process. Therefore, the advantage of media high in social presence is that the attention and motivation required on the part of the receiver, which is the first step toward elaboration, has in some part been achieved.

In contrast, the receiver can easily ignore messages sent in media that is low in social presence [43]. The receiver does not have to obligate himself to be at a specific time or place. This means that the message has to compete with other activities, such as other messages transmitted in high social presence media, to get the attention of the receiver. The receiver can read the message at will and may even decide not to read the message. For example, if the sender attempts to communicate with the receiver through a low social presence medium like email, which does not require the receiver to commit to a specific location and time, the receiver may skim through multiple messages and never read the sender's email.

This does not mean that by merely attempting to communicate using a medium high in social presence, one will be successful at obtaining both the attention and motivation of the receiver. For example, if a receiver gets a phone call from a telemarketer during dinner, the receiver can either ignore the call or answer the phone. If the receiver answers the phone, the sender still has gained the attention of the receiver. If the receiver agrees to hear the sender, the sender has in part motivated the receiver. However, if the receiver hangs up the phone, the sender was successful at gaining the receiver's attention but not motivation. Hence, in order to engage in communication with a high social presence, both the receiver and sender must agree to use the communication media.

The sender must get the attention of the receiver if he or she is to evoke a change in the receiver's understanding [42]. The higher the social presence required by the media, the higher the degree of commitment the receiver has to have to participate in the communication process. When individuals must obligate themselves to a specific place and time for communication, their commitment level is high. However, individual commitment is low when individuals are not bound to any specific location or time for communication to occur. As the level of social presence increases, the effort and attention devoted to the communication process also increases. This is a direct reflection of the level of attention and motivation involved in the communication process. This does not imply that individuals that choose to engage in media low in social presence will lack motivation. However, the sender cannot be sure of what level of attention and motivation their message may receive. This leads to our second proposition.

Proposition $2 a$ Receivers who agree to use high social presence media will have high levels of attention and be motivated to process the message.

The more urgent the contents of the message, the more the sender would want to know that: (1) the receiver has seen the message (i.e., that the sender has gotten the attention of receiver) and (2) the receiver will elaborate on the message and respond immediately (i.e., is motivated to think about the message). The "urgency" or need for immediate attention, coupled with the task, has proven to be an important determinant of medium selection [6], [45]. To ensure that the sender has the receiver's full attention and motivation, the sender will use a medium high in social presence, such as a face-to-face meeting, to communicate the message to the receiver. However, when distance makes a face-to-face meeting unrealistic, the sender will engage in media with moderate social presence (same time, different place), such as a real-time synchronous chat room or a telephone to ensure an immediate response.

Proposition $2 b$ When senders require an immediate response from the receiver, they will choose a medium with a higher social presence.

Ability to Process If individuals are motivated, they are inclined to begin the elaboration process. The degree to which they can elaborate will depend on their ability to process the message received. Hence, the next hurdle to elaboration is to ensure that the receiver has the ability to process the information, the final step toward elaboration. Individuals often 
have a limited ability to process information and therefore are less able to sufficiently evaluate each message they receive [46]. The ability to process is impacted by factors such as the intelligence to follow the argument, whether there are enough sources of information to fully gasp the issue being discussed, and whether there is enough time to process and/or reprocess the information.

The modality of the message has a direct effect on the receiver's ability to process the message [35], [36]. One important media attribute is the ability to allow the receiver to reprocess the information or in the words of Petty and Cacioppo "to elaborate at will." However, once an individual has had the opportunity to fully elaborate on the message, additional unwanted exposure will only decrease the message acceptance [35]. Dennis and Valacich introduced a similar term to repetition called reprocessability, defined as "the extent to which a message can be reexamined or processed again within the context of the communication event" [47, p. 3]. Reprocessability avoids the negative effect of overexposure by allowing the receiver to dictate the amount of viewing.

Media with high social presence differ from those with low social presence in their ability to provide reprocessability, allowing the receiver the ability to elaborate at will. In general, media with low social presence provide a higher level of reprocessability that allows the receiver to stop and think over important or difficult points [47]-[49]. When a message is sent via a low social presence medium, the receiver has more time to comprehend the message. The receiver also has access to more sources of information. In the case of an email message, for example, additional sources could be in the form of web links and/or numerous documents attached to the email. Media low in social presence enable the receiver to access the information repeatedly until he or she fully comprehends it.

In contrast, by social convention, media high in social presence do not allow individuals to elaborate at will. There is a perception or need to respond quickly to avoid disrupting the conversation when individuals are communicating in real time [4], [47]. This is a major drawback because when presented with the same amount of information to process, reducing the amount of time one has to process it increases the information load [50]. Media high in social presence allow the receiver little ability to access multiple sources of information, or the ability to reprocess the information (i.e., reprocessability). Media high in social presence can also obscure the receiver's memory, making it difficult to draw upon previously stored knowledge [51], [52]. As a result, the ability to process in low social presence media is greater than media high in social presence; thus, we offer our third proposition.

Proposition 3 The level of social presence provided by the media has an inverse relationship with the receiver's ability to process the message.
Message Complexity Complex messages require a high ability to process. However, the ability to process in a high social presence media is relatively low. Individuals have a natural constraint on the amount of information they can accept, process, and recall [53]. As a result, when faced with a highly complex message, a receiver can quickly become overwhelmed with information. This is commonly referred to as information overload, "a state in which the amount of information that merits attention exceeds an individual's ability to process it" [44, p. 1]. Speier and Morris explain the mental strain caused by increases in task complexity:

Under conditions of high task complexity, subjective mental workload increases as more data elements are evaluated and retained in working memory (Rossano and Moak 1998). Decision makers retain as much data as their working memory allows until the amount of data increases to a point where their ability is constrained (March and Simon 1958; Miller 1956). Once this point is reached, decision makers will resort to cognitive simplification strategies (Streufert 1973) that typically result in decreased decision quality, increased decision time, and/or increased confusion (Chewning and Harrell 1990; Jacob et al. 1974a, 1974b; Johnson and Payne 1985). In such cases, decision makers may seek to reduce cognitive workload (Beach and Mitchell 1978) by relying on human perceptual processes that consume less time than cognitive or analytical processes (Kirlik et al. 1993; Payne et al. 1988). [54, p. 401]

Because humans have limited extended working memory, the more complex a message, the less likely an individual will be able to elaborate on it in a high social presence medium. When the receiver does not have enough time or access to information to process the message, we believe that the receiver will reject the message, delay the decision, or look for peripheral cues [36]. For example, if a CEO is faced with a request from a $\mathrm{CIO}$ in a high social presence media regarding funding of a highly complex technical project, he or she may not have the ability to process the information because of a lack of time, information, or technical expertise. The CEO will do one of three things: (1) reject the request because of his or her lack of ability to process; (2) use source cues, such as source creditability, and accept the recommendation from the CIO (trusting the CIO expertise); or (3) table the issue for further discussion (until he or she has the ability to process it).

Proposition $4 a$ Individuals who are faced with a complex message sent using a medium with high social presence will reject the message, delay the decision, or look for peripheral cues.

Proposition $4 b$ Individuals who are faced with a complex message sent using a medium with low social presence and who are motivated will elaborate on the message. 
The opposite is true with simple, intuitive messages. When presented with a relatively simple intuitive message in a high social presence media that requires little ability to process, the receiver will fully elaborate on the message, which in turn increases the opportunity of attitude change.

Proposition $4 c$ Individuals who are faced with simple, intuitive messages sent in a medium with high social presence will be more likely to elaborate on the message.

Media Switching Taken together, our first four propositions present a paradox in the use of rich media high in social presence. Media that allow the receiver the highest ability to process may not garner the attention and motivation of the receiver. Ironically, there appears to be an inverse relationship between attention and motivation with the ability to process (see Fig. 2).

As the ability to ensure that motivation and attention is present goes up, the ability to process goes down, and vice versa. Senders are therefore left with a dilemma and must balance attention and motivation with the ability to process. Determining which messages require which media has a significant effect on the sender's ability to facilitate understanding in the receiver.

How then how does the sender gain the receiver's attention and motivate the receiver to process his or her message while also giving the receiver the ability to process the message? Because each type of media offers advantages over the other, choosing one single medium may prove less effective. The use of mixed media or media switching can avoid the disadvantages of both high social presence media and low social presence media while capitalizing on their advantages. When individuals want to get the attention of the receiver and motivate them, they should use a medium high in social presence. This ensures the sender that he or she has some level of the receiver's attention and motivation. However, when deep thought and deliberation are needed to process the message, the sender should use a medium low in social presence to give the receiver time to consider the issue fully.

Saunders and Jones suggest that a variety of media are needed at different stages in the decision making process and that decision makers should manage the information flow via media selection to prevent information overload [55]. Dennis and Valacich suggest that media switching could provide the best performance for a task that requires both information dissemination and convergence on a decision [47].

In a literature review of 200 different laboratory studies involving groups of three or more members, which engaged in communication and/or decision making through a computer-based group support system, Fjermestad and Hiltz highlighted the lack of research in mixed media, but were careful to note that, despite this, the results of studies testing mixed media have been generally supportive of mixed media's effectiveness as a communication method [56]. Ocker et al. hypothesize that groups that used mixed media would be better able to plan and organize their work [57]. They found that the groups that used mixed media produced more creative and higher quality solutions than groups using just one medium of communication. D'Ambra and Ronald conducted a longitudinal case study testing media richness by measuring the performance of 16 tasks with varying degrees of equivocality, and found that a combination of face-to-face and telephone communication was used more often for higher equivocal tasks [58].

Proposition 5 Switching between high and low social presence media will be the optimum choice for exchanging information for complex tasks requiring attention, motivation, and the ability to process when the sender wants the receiver to objectively elaborate on the message.

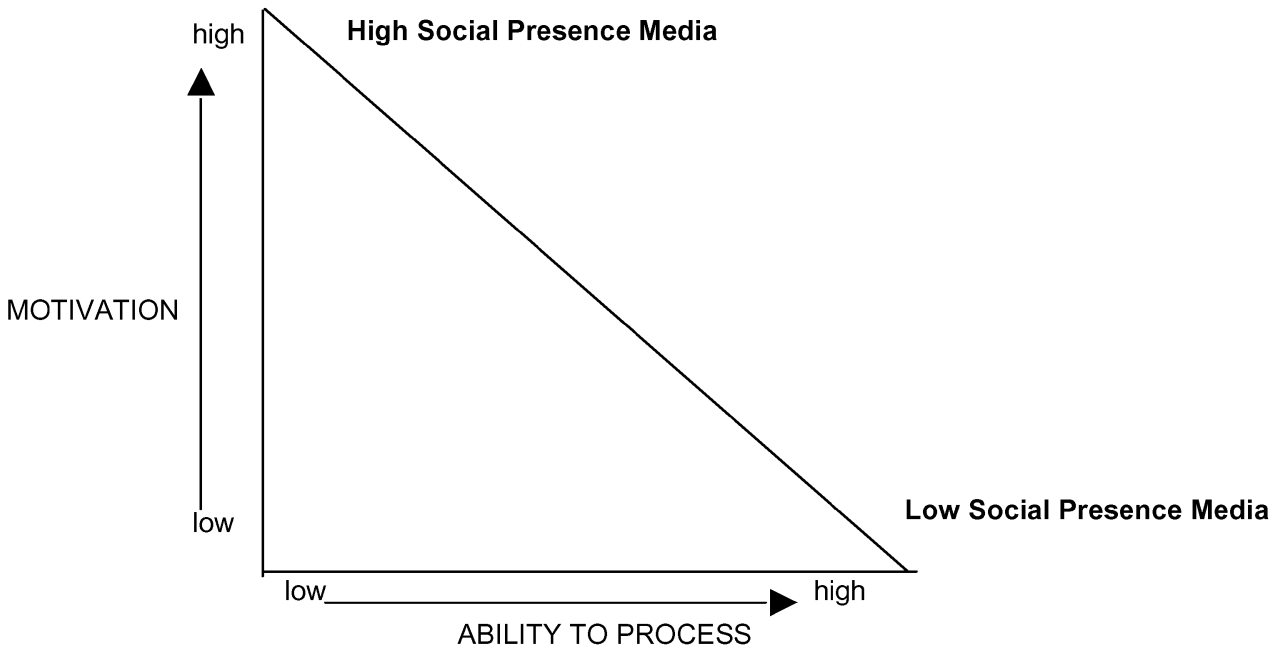

Fig. 2. Inverse relationship between motiviation and ability to process. 


\section{Discussion}

Much of the prior research and theorizing on the choice of media and the effects of using different media has been grounded in social psychology. As a result, much of the research has been directed at establishing a given medium's ability to embody the social presence of the sender and receiver. Based on prior research on social presence, it would seem that a medium high in social presence is best for communicating simple, well-known ideas and ineffective at communicating complex and less-known ideas. With the introduction of new media we are finding mixed results.

In order to address the issue of a given medium's effectiveness, we have proposed a shift to a cognitive-based approach. By taking a cognitive-based approach to assessing media effectiveness, we are able to return to the premise offered by Daft and others and begin to understand how media effects a change in the receiver's understanding or facilitates understanding. As a result, we propose a model that we believe explains the cognitive effects of media. We will now use a prior study to demonstrate the theory.

\section{Reviewing Past Media Richness Research In} this section, we briefly revisit past research on media use and performance. Our goal is to draw contrasts between the media richness theory and the cognitive-based view (CBV) and to investigate the alternative interpretations and insights that the current theory may provide, to explain the original results.

An example in which the media richness theory fails to explain communication processes is reported in Markus when she argues that an expanded definition of richness for email does not explain behavior in her study [16]. As we will illustrate below, CBV can explain many of the critical incidents presented in the study as examples of the difficulty in applying the media richness theory.

In her study, an instrument was used to capture individual sensitivities to media usage by providing hypothetical communication tasks (reasons for communicating) [16]. Comparing these media selections to those predicted by the media richness theory, she found mixed support for the media richness theory. For example, "to communicate something complicated to someone far away," only $42.9 \%$ of the respondents selected the telephone, the medium that was predicted by the media richness theory [16, p. 521].

In another example from this study, one participant effectively used email for a series of highly equivocal communications requiring the resolution of disagreement, contrary to media richness predictions [16, p. 516]. CBV would suggest that the use of email would be highly appropriate in this situation.
The participants all worked together in the same company, two in one department (Ted, a supervisor over Mike) and two in another department (Sheila and an unnamed subordinate). Considering the task at hand, all of the individuals seemed to be familiar with the general activity of processing of payments but unaware of information specific to the situation with which they were confronted. The use of low social presence media to convey this information over email would seem to be appropriate. Low social presence media, like email, would allow the receivers time to deliberate and think over their own interpretation of what the information means, and seek additional sources of information when needed. This is exactly what Ted did when given information from Mike about payment delays. As noted by Markus, when Ted's interpretation of the information was different from his subordinate's, he went to a third participant (Sheila) for further consideration [16]. CBV would suggest that in this context, individuals do not have to communicate face-to-face. Many of the communication processes seen here are those of conveyance, requiring others to deliberate and come up with their interpretations. Email would seem to be sufficient for these communication processes.

Markus also provides an empirical example of media switching when she notes the importance of media switching, using email to send information, followed by a phone call to converge to a shared agreement on action to take [16, p. 517]. Markus writes:

Ted's assistant came to the door to announce an emergency telephone call from one of his direct subordinates: "He said he sent you a message about it." As he picked up the phone, Ted pulled up the subordinate's message on his terminal screen. For a few seconds, Ted read the message in silence. He then spoke a few short sentences into the phone and hung up. [16, p. 517]

The media richness theory would suggest that this example indicates the lack of richness inherent in email (or it would have been used for the entire interaction). Using $\mathrm{CBV}$, the interpretation of the action above is different. From this perspective, we would argue that the capability to provide reprocessability for a large volume of information would mean that the richest medium for conveying the information required to resolve this task would be email; thus, individuals in the study chose it. The subordinate had "the whole thing written down at 1:04," suggesting that a large amount of complex information (negotiations) was to be conveyed [16, p. 517]. Low social presence media was useful to allow the recipient (the supervisor) time to read and deliberate on the information and come up with an answer.

Immediate feedback was necessary for the response; thus, the phone call was used to get the answer 
from the supervisor. Although we are not provided with the content of the telephone response, it seems appropriate that it may have contained an explanation for the answer, such that a convergence on the final result between the supervisor and the subordinate was enabled through a medium providing moderate social presence (higher than the original email): the telephone. Thus, our theory would predict this media-switching behavior-(email to share information and provide the ability to elaborate, followed by telephone to induce greater motivation to process-as the most effective).

\section{Implications for Research AND Practice}

One major implication for research is the identification of a much understudied area, the cognitive processing of communication. Although there is a plethora of research on the social process of communication, very little has been done in understanding the original premise of the media richness theory: media's ability to effect a change in understanding. By taking an individual cognitive approach, we, as researchers, are better able to answer research questions pertaining directly to media's effectiveness.

When individuals are presented with a complex message in a high social presence medium, the receiver will lack the ability to process the message and will look for peripheral cues. The use of peripheral cues will inherently lead to biased processing of the message [35], [36]. Studies have indicated cues such as source credibility or likeability have a greater effect on processing when they are presented through video or audio as opposed to printed media [39], [59]. This can have profound implications since both social presence and media richness theories posit that face-to-face meetings are better for highly equivocal tasks.

Previous research seems to confirm that individuals prefer media low in social presence for processing large amounts of information and media high in social presence for small amounts of information. Trevino et al. found that smaller amounts of information were transmitted in what we would classify as media high in social presence, or what they referred to as high interactivity media [17]. Te'eni et al. conducted a field study by examining the contents of an organization's email communications over a 12-month period, coding the medium, message, and communication strategy [4]. They found that individuals preferred certain media for certain messages. In particular, individuals tended to use less interactive media, or what we would classify as media low in social presence, for larger messages.

Past research has yet to fully explore the effects of media switching (telephone, email, videoconferences) on decision making [56]. When individuals are presented with relatively simple information or tasks, media choice may have little effect on performance. Unfortunately the studies undertaken in the past comparing face-to-face communication to computer-mediated communication usually center on simple tasks [56]. As a result, we as a research community may not fully understand the implications of a lack of fit between the message and medium. Future studies could empirically test the propositions. Laboratory studies could be conducted using the level of message comprehended as the dependent variable, while varying the media and the complexity of the message. Field studies could survey managers, asking them what type of media they use when communicating simple and complex messages. Case studies could be conducted by observing the communication patterns of managers within an organization.

How important is social presence to media effectiveness? Several studies testing the effects of video channel have not found support for a positive relationship between media effectiveness and social presence. Olson et al. found that groups using video for instructional communication were often distracted from the task at hand [60]. Several studies have found that members using video often spent less time stating and clarifying issues [61] and were less task focused than their audio-only counterparts [62]. Kozma found that there were short episodes of engagement in which learners would pay attention to material presented through video channel after which their attention shifted away [63]. Meanwhile, Phillips and Santoro found that leaner media directed users away from nontask-related communication by focusing attention on the task at hand [64]. In short, there is both past and emerging literature questioning whether social presence is positively related to media effectiveness. In some cases, research is beginning to show that communication media high in social presence can distract from task performance [60]-[62].

The number of receivers may also impact the relationship between attention, motivation, and ability to process. In groups or large audiences, some receivers may not actively engage in processing the messages and will assume others will do it for them. This is referred to as "free riding." This lack of attention and motivation can go unnoticed because the sender is less able to monitor the behavior of the receivers. While free riding can occur in either high or low social presence media, it is likely to be worse in low social presence media because monitoring the behavior of others is more difficult. Past research has shown that members of electronic groups are more likely to ignore information [64]. Thus, we expect that the potential motivation and attention issues encountered when using low social presence media are likely to be felt even more strongly in a team setting. 
We believe that the CBV of media also has important implications for managers, employees, and executives. The media richness theory recommends that managers will be more effective by matching richer media to more equivocal tasks. Consequently, many managers may have been led to believe that they should attempt to communicate complex ideas through a medium higher in social presence, like face-to-face interaction. This could lead managers, at times, to present complex arguments to individuals who possess neither the needed attention and motivation nor the ability to process them. As a result, their ideas and/or suggestions are often glazed over by supervisors or subordinates who may never fully consider the true merits embedded in the arguments. This will result in superficial or biased evaluations of ideas instead of presenting a message based on the cognitive requirement to process the information. Hopefully, the results of this paper will provide managers with some recommendations for media use to help ensure that their message will be fully considered.

\section{CONCLUSION}

We conclude with two points about the paradox of richness. First, the use of rich media high in social presence induces increased motivation but decreased ability to process, while the use of lean media low in social presence induces decreased motivation but increased ability to process. This runs counter to past research, which has overwhelmingly proposed that as task complexity increases, so should the level of richness and social presence of the media used. As Sheridan concluded, in a study of teleoperation, it is not always the sense of presence that is vital but having sufficient information in the appropriate format and the ability to duly consider it [65]. A sense of presence may at worst be a "concomitant benign phenomenon" or at best a "distraction" [65, p. 120]. By understanding the paradoxical effects of rich media high in social presence, we may be better able to select and use the most appropriate sets of media to accomplish our goals.

Second, social psychology, media richness, and social presence have long formed the foundation for research and theory on media choice and the effects of media use. This focus has lead to much valuable research. We believe that cognitive psychology can play an equally important role in researching and theorizing about media choice and the impact of using media, especially new digital media. We have proposed a cognitive-based view of media choice in an attempt to draw attention to the lack of research directed toward media's ability to evoke a change in understanding and the paradoxical impacts of using rich media high in social presence. We hope this encourages debate and prompts others to consider the cognitive foundations underpinning social interaction.

\section{REFERENCES}

[1] D. Te'eni, "Review: A cognitive-affective model of organizational communication for designing it," MIS Quart., vol. 25, no. 2, pp. 251-312, 2001.

[2] J. Short, E. Williams, and B. Christie, The Social Psychology of Telecommunications. New York: Wiley, 1976.

[3] R. L. Daft and R. H. Lengel, "Organizational information requirements, media richness and structural design," Manage. Sci., vol. 32, no. 5, pp. 554-571, 1986.

[4] D. Te'eni, A. Sagie, D. G. Schwartz, N. Zaidman, and Y. Amichai-Hamburger, "The process of organizational communication: A model and field study," IEEE Trans. Profess. Commun., vol. 44, no. 1, pp. 6-20, 2001.

[5] A. R. Dennis and S. T. Kinney, "Testing media richness theory in new media: The effects of cues, feedback, and task equivocality," Inform. Syst. Res., vol. 9, no. 3, pp. 256-274, 1998.

[6] D. Straub and E. Karahanna, "Knowledge worker communications and recipient availability: Toward a task closure explanation of media choice," Org. Sci., vol. 9, no. 2, pp. 160-175, 1998.

[7] P. Carlson and G. B. Davis, "An investigation of media selection among directors and managers: From 'self' to “other' orientation,” MIS Quart., vol. 22, no. 3, pp. 335-362, 1998.

[8] N. Kock, "Can communication medium limitations foster better group outcomes? An action research study," Inform. Manage., vol. 34, no. 5, pp. 295-305, 1998.

[9] N. Kock and R. Davison, "Can lean media support knowledge sharing? Investigating a hidden advantage of process improvement,” IEEE Trans. Eng. Manage., vol. 50, no. 2, pp. 151-163, 2003.

[10] C. F. Bond and L. J. Titus, "Social facilitation: A meta-analysis of 241 studies," Psych. Bull., vol. 94, no. 2, pp. 265-292, 1983.

[11] R. S. Baron, "Distraction-conflict theory: Progress and problems," in Advances in Experimental Social Psychology, L. Berkowtiz, Ed. New York: Academic, 1986, pp. 1-40.

[12] I. Simonson, Z. Carmon, R. Dhar, and A. Drolet, "Consumer research: In search of identity," Annu. Rev. Psych., vol. 52, no. 1, pp. 249-275, 2001.

[13] J. Short, E. Williams, and B. Christie, The Social Psychology of Telecommunications. New York: Wiley, 1978.

[14] R. L. Daft and N. B. Macintosh, "A tentative exploration into the amount and equivocality of information processing in organizational work units," Admin. Sci. Quart., vol. 26, no. 2, pp. 207-224, 1981.

[15] R. L. Daft, R. H. Lengel, and L. K. Trevino, "Message equivocality, media selection, and manager performance," MIS Quart., vol. 11, no. 3, pp. 355-366, 1987. 
[16] M. L. Markus, "Electronic mail as the medium of managerial choice," Org. Sci., vol. 5, pp. 502-527, 1994.

[17] L. Trevino, R. H. Lengel, and R. L. Daft, "Media symbolism, media richness, and media choice in organizations," Commun. Res., vol. 14, no. 5, pp. 553-574, 1987.

[18] G. Russ, R. Daft, and R. Lengel, "Media selection and managerial characteristics in organizational communications," Manage. Commun. Quart., vol. 4, no. 2, pp. 151-175, 1990.

[19] L. Trevino, R. L. Daft, and R. H. Lengel, "Understanding managers' media choices: A symbolic interactionist perspective," in Organizations and Communication Technology, J. Fulk and C. W. Steinfeld, Eds. Newbury Park, CA: Sage, 1990, pp. 71-95.

[20] J. Whitfield, B. Lamont, and V. Sambamurthy, "The effects of organization design on media richness in multinational enterprises," Manage. Commun. Quart., vol. 10, no. 2, pp. 209-226, 1996.

[21] M. Zack, "Electronic messaging and communication effectiveness in an ongoing work group," Inform. Manage., vol. 26, no. 4, pp. 231-241, 1994.

[22] B. Caldwell, S. Uang, and L. Taha, "Appropriateness of communications media use in organizations: Situation requirements and media characteristics,” Behav. Inform. Technol., vol. 14, no. 4, pp. 199-207, 1995.

[23] J. D’Ambra, R. E. Rice, and M. O’Connor, "Computer-mediated communication and media preference: An investigation of the dimensionality of perceived task equivocality and media richness," Behav. Inform. Technol., vol. 17, no. 3, pp. 164-174, 1998.

[24] A. Lee, "Electronic mail as a medium for rich communication: An empirical investigation using hermeneutic interpretation," MIS Quart., vol. 18, no. 2, pp. 143-157, 1994.

[25] R. Rice and D. Shook, "Relationships of job categories and organizational level to use of communications channels, including electronic mail: A meta-analysis and extension,” J. Manage. Studies, vol. 27, no. 2, pp. 195-223, 1990.

[26] K. Fulk, C. W. Steinfeld, J. Schmitz, and J. G. Power, "A social information processing model of media use in organizations," Commun. Res., vol. 14, no. 5, pp. 429-552, 1987.

[27] J. Schmitz and J. Fulk, "Organizational colleagues, media richness, and electronic mail," Commun. Res., vol. 18, no. 4, pp. 487-523, 1991.

[28] S. T. Kinney and R. Watson, "The effect of medium and task on dyadic communication," in Proc. 13th Int. Conf. Inform. Syst., Dallas, TX, 1992, pp. 107-117.

[29] B. E. Mennecke, J. S. Valacich, and B. C. Wheeler, "Uncovering limitations to media richness theory: The effects of varying media and tasks on user perceptions and task performance," Group Decision Negotiation, vol. 9, no. 6, pp. 507-529, 2000.

[30] M. L. Markus, "Toward a 'critical mass' theory of interactive media: Universal access, interdependence, and diffusion,” Commun. Res., vol. 14, no. 5, pp. 491-511, 1987.

[31] J. R. Carlson and R. W. Zmud, "Channel expansion theory and the experiential nature of media richness perceptions,” Acad. Manage. J., vol. 42, no. 2, pp. 153-170, 1999.

[32] C. A. Ellis, S. Gibbs, and G. Rein, "Groupware: The research and development issues," Commun. ACM, vol. 34, no. $1,1991$.

[33] G. DeSanctis and B. Gallupe, "Group decision support systems: A new frontier," Database: Adv. Inform. Syst., vol. 16, no. 2, pp. 2-10, 1985.

[34] G. DeSanctis and R. B. Gallupe, "A foundation for the study of group decision support systems," Manage. Sci., vol. 33, no. 5, pp. 589-609, 1987.

[35] R. E. Petty and J. T. Cacioppo, "The elaboration likelihood model of persuasion," in Advances in Experimental Social Psychology, L. Berkowitz, Ed. Orlando, FL: Academic, 1986, vol. 19, pp. 123-205.

[36] R. E. Petty and J. Cacioppo, Communication and Persuasion: Central and Peripheral Routes to Attitude Change. New York: Springer-Verlag, 1986.

[37] R. E. Petty and D. T. Wegener, "Attitude change," in The Handbook of Social Psychology, D. Gilbert, S. Fiske, and G. Lindzey, Eds. New York: McGraw-Hill, 1998, pp. 323-390.

[38] S. Chaiken, "Heuristic versus systematic information processing and the use of source versus message cues in persuasion," J. Personality Social Psych., vol. 39, no. 5, pp. 752-756, 1980.

[39] S. Chaiken and A. H. Eagly, "Communication modality as a determinant of persuasion: The role of communicator salience,” J. Personality Social Psych., vol. 45, no. 2, pp. 241-256, 1983.

[40] S. Chaiken and Y. Trope, Dual-Process Theories in Social and Cognitive Psychology. New York: Guilford, 1999.

[41] J. Meyers-Levy and P. Malayiya, "Consumers' processing of persuasive advertisements: An integrative framework of persuasion theories,” J. Market., vol. 63, pp. 45-60, 1999.

[42] W. Thorngate, "The economy of attention and the development of psychology," Can. Psych., vol. 31, no. 3, pp. 262-271, 1990.

[43] S. S. Kahai and R. B. Cooper, "Exploring the core concepts of media richness theory: The impact of cue multiplicity and feedback immediacy on decision quality," J. Manage. Inform. Syst., vol. 20, no. 1, pp. 263-299, 2003.

[44] U. Schultze and B. Vandenbosch, "Information overload in a groupware environment: Now you see it, now you don't,” J. Org. Comput. Electron. Commerce, vol. 8, no. 2, pp. 127-148, 1998.

[45] A. H. Picot, H. Klingenberg, and H. P. Kranzle, "Office technology: A report on attitudes and channel selection from field studies in Germany," in Communication Yearbook, M. Burgoon, Ed. Beverly Hills, CA: Sage, 1982, vol. 6, pp. 674-692.

[46] W. J. McGuire, "The nature of attitude change," in The Handbook of Social Psychology, G. Lindzey and E. Aronson, Eds. Reading, MA: Addison-Wesley, 1969, pp. 137-314.

[47] A. R. Dennis and J. S. Valacich, "Rethinking media richness: Toward a theory of media synchronicity," in Proc. 32th Annu. Hawaii Int. Conf. Syst. Sci., Los Alamitos, CA, 1999, pp. 1-10. 
[48] S. Chaiken and A. H. Eagly, "Communication modality as a determinant of message persuasiveness and message comprehensibility,” J. Personality Social Psych., vol. 45, no. 2, pp. 241-56, 1976.

[49] P. Wright, "Cognitive responses to mass media advocacy," in Cognitive Responses in Persuasion, R. E. Petty, T. M. Olstrom, and T. C. Brock, Eds. Mahwah, NJ: Lawrence Erlbaum, 1981, pp. 263-282.

[50] M. L. Grise and R. B. Gallupe, "Information overload: Addressing the productivity paradox in face-to-face electronic meetings," J. Manage. Inform. Syst., vol. 16, no. 3, pp. 157-185, 2000.

[51] M. A. Shapiro and A. Lang, "Making television reality: Unconscious processes in the construction of social reality," Commun. Res., vol. 18, no. 5, pp. 685-705, 1991.

[52] M. A. Shapiro and D. G. McDonald, "I'm not a real doctor, but I play one in virtual reality: Implications of virtual reality for judgments about reality," J. Commun., vol. 42, no. 4, pp. 94-114, 1992.

[53] G. A. Miller, "The magical number seven, plus or minus two: Some limits on our capacity for processing information," Psych. Rev., vol. 63, no. 2, pp. 52-60, 1956.

[54] C. Speier and M. Morris, "Influence of query interface design,” MIS Quart., vol. 27, pp. 397-423, 2003.

[55] C. Saunders and W. J. Jones, "Temporal sequences in information acquisition for decision making: A focus on source and medium,” Acad. Manage. Rev., vol. 15, no. 1, pp. 29-46, 1990.

[56] J. Fjermestad and S. T. Hiltz, "An assessment of group support systems experimental research: Methodology and results," J. Manage. Inform. Syst., vol. 15, no. 3, pp. 7-149, 1998.

[57] R. Ocker, J. Fjermestad, S. R. Hiltz, and K. Johnson, "Effects of four modes of group communication on the outcomes of software requirements determination," J. Manage. Inform. Syst., vol. 15, no. 1, pp. 99-118, 1998.

[58] J. D’Ambra and R. E. Ronald, "Multimethod approaches for the study of computer-mediated communication, equivocality, and media selection," IEEE Trans. Profess. Commun., vol. 37, no. 4, pp. 231-240, 1994.

[59] V. Andreoli and S. Worchel, "Effects of media, communicator, and message position on attitude change," Public Opinion Quart., vol. 42, no. 1, pp. 59-70, 1978.

[60] J. S. Olson, G. M. Olson, and D. K. Meader, "Face-to-face group work compared to remote group work," in Video-Mediated Communication, K. E. Finn, A. J. Sellen, and S. B. Wilbur, Eds. Mahwah, NJ: Lawrence Erlbaum, 1997.

[61] L. Festinger and N. Maccoby, "On resistance to persuasive communications," J. Abnormal Social Psych., vol. 68, no. 4, pp. 359-366, 1964.

[62] G. M. Stephenson, K. Ayling, and D. R. Rutter, "The role of visual communication in social exchange," Brit. J. Social Clin. Psych., vol. 15, no. 2, pp. 113-120, 1976.

[63] R. Kozma, "Implications of instructional psychology for the design of educational television," Educ. Commun. Technol. J., vol. 34, no. 1, pp. 11-19, 1986.

[64] G. M. Phillips and G. M. Santoro, "Teaching group discussion via computer-mediated communication," Commun. Educ., vol. 38, no. 2, pp. 151-161, 1989.

[65] T. B. Sheridan, "Musings on telepresence and virtual presence," Presence, vol. 1, no. 1, pp. 120-126, 1992.

Lionel P. Robert is a doctoral student in Information Systems at the Kelley School of Business at Indiana University. His research focuses on team collaboration, trust, and social identity in virtual environments. Robert is a BAT doctoral fellow and KPMG scholar. He completed his M.S. in industrial management at Clemson University and an M.S. in telecommunications at the University of Louisiana at Lafayette.

Alan R. Dennis holds the John T. Chambers Chair of Internet Systems at the Kelley School of Business at Indiana University. His research focuses on team collaboration, knowledge management, and the use of the internet. He is the Publisher of MIS Quarterly Executive and serves on the editorial boards of The Journal of Management Information Systems, The Journal of the Association for Information Systems, Journal of Computer Mediated Communication, and The International Journal of e-Collaboration. 